Provided for non-commercial research and education use. Not for reproduction, distribution or commercial use.

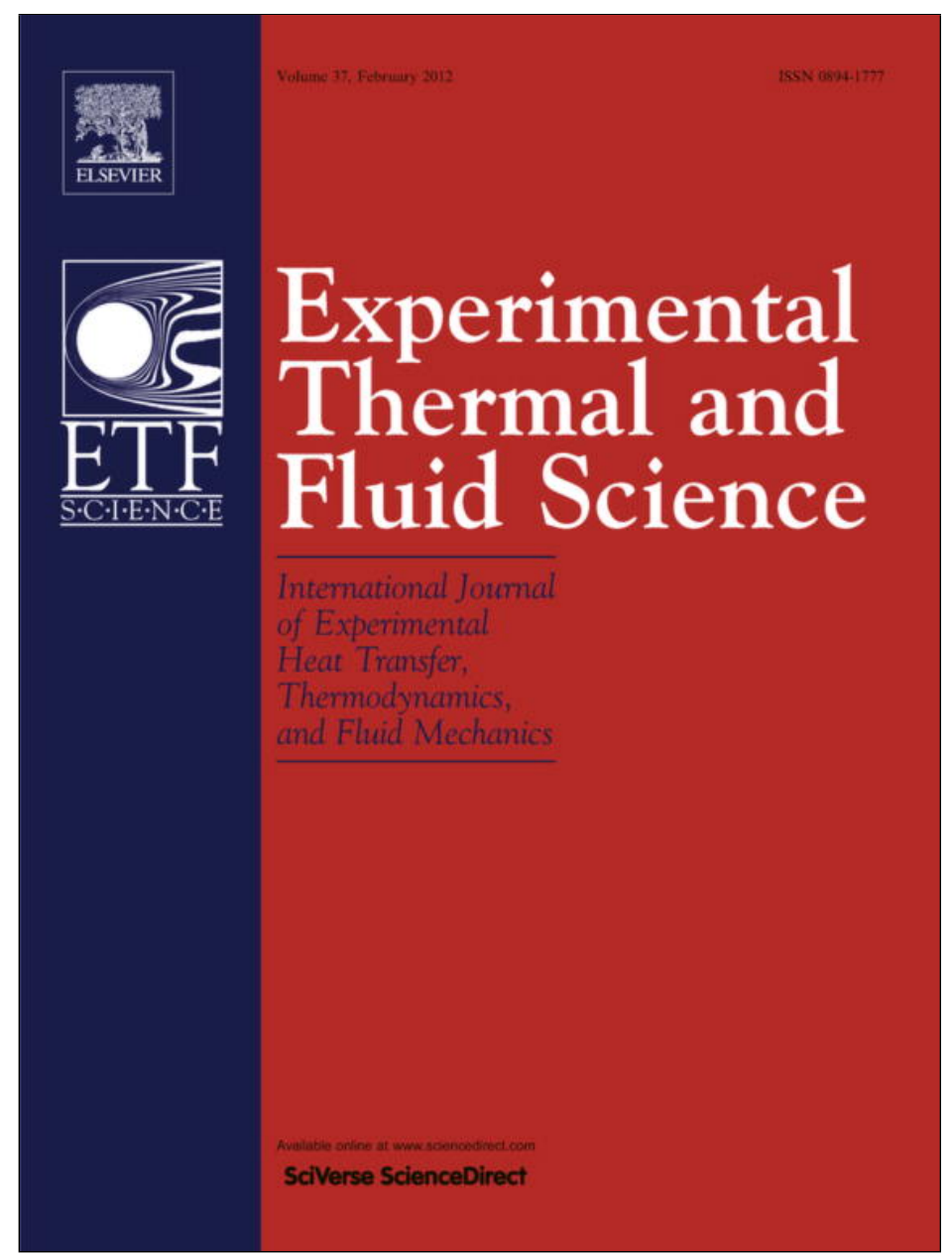

This article appeared in a journal published by Elsevier. The attached copy is furnished to the author for internal non-commercial research and education use, including for instruction at the authors institution and sharing with colleagues.

Other uses, including reproduction and distribution, or selling or licensing copies, or posting to personal, institutional or third party websites are prohibited.

In most cases authors are permitted to post their version of the article (e.g. in Word or Tex form) to their personal website or institutional repository. Authors requiring further information regarding Elsevier's archiving and manuscript policies are encouraged to visit:

http://www.elsevier.com/copyright 


\title{
Experimental investigation of dryout of propane in uniformly heated single vertical mini-channels
}

\author{
Muhammad Hamayun Maqbool, Björn Palm*, Rahmatullah Khodabandeh \\ Applied Thermodynamics and Refrigeration, EGI, KTH, Stockholm, Sweden
}

\section{A R T I C L E I N F O}

\section{Article history:}

Received 9 July 2011

Received in revised form 20 October 2011

Accepted 24 October 2011

Available online 2 November 2011

\section{Keywords:}

Minichannels

Dryout

Propane

Experimental study

CHF

\begin{abstract}
A B S T R A C T
This article presents dryout results of propane in single vertical circular minichannels made of stainless steel with internal diameters of $1.70 \mathrm{~mm}$ and $1.224 \mathrm{~mm}$. The heat flux is increased in steps up to occurrence of dryout. The effects of different parameters such as mass flux, saturation temperature, vapour quality and internal diameter on the dryout are investigated. The results show that the dryout heat flux increases with the increase in mass velocity, with the decrease of vapour quality and with the increase of internal diameter. Almost no effect of saturation temperature on dryout heat flux is observed. Generalised CHF correlations developed for macro and micro scale from the literature are also compared with the experimental results.
\end{abstract}

(ㄷ) 2011 Elsevier Inc. All rights reserved.

\section{Introduction}

Flow boiling in minichannels is presently one of the leading research fields in boiling heat transfer. Minichannels offer several advantages such as increased heat transfer, low fluid inventory and thereby increased safety when using flammable refrigerants, and low cost and reduced size resulting in increased compactness. The main application areas of minichannels include electronic cooling, air conditioning systems in the automotive industry and biomedical engineering. The technology may in the future also be used in heat pump and refrigeration systems. In the last two decades, the heat transfer research in minichannels has been focused on using HFC refrigerants. The requirement to replace HFC's in the near future due to environmental concerns has encouraged the research community to find potential natural refrigerants capable of replacing HFC's. Therefore in the last decade, some flow boiling studies have been done to capture the behaviour of natural refrigerants in minichannels.

Propane is one of the potential candidates to replace HFC fluids. Propane does not have any ozone depletion potential (ODP) and has very low global warming potential (GWP). It is non-toxic, chemically stable, compatible with most materials used in HFC equipment and is miscible with commonly used compressor lubricants. Propane has very good thermodynamic and transport

\footnotetext{
* Corresponding author. Address: Brinellvägen 68, SE 100 44, Stockholm, Sweden. Tel.: +46 (0)8 790 7453; fax: +46 (0)8 204161 .

E-mail addresses: maqbool@kth.se (M.H. Maqbool), bpalm@energy.kth.se (B. Palm), rahmat@energy.kth.se (R. Khodabandeh).
}

properties and also properties that closely resemble HFC refrigerants, allowing it to be used without re-design of existing systems. However, the main concern with the use of propane as refrigerant is its high flammability. By using minichannel heat exchangers, the fluid inventory will be low, and thereby the risks connected with the flammability will be reduced [1].

The terms critical heat flux (CHF) and dryout are both used to describe a situation when the heated surfaces in an evaporator are no longer wetted by the liquid [2,3]. Strictly speaking, the way in which this situation is reached determines whether it should be termed critical heat flux or dryout. Critical heat flux could appear at any vapour fraction and represents the upper limit of the heat flux where liquid is still in contact with the surface. Dryout appears at high vapour fraction, independently of heat flux, when there is not sufficient liquid left to fully wet the walls of the channel. At dryout, the wall temperature starts increasing due to the heat transfer deterioration. In the literature, the terms are used less strict, and in the following, we will use the term CHF even though dryout would be more adequate. In designing a two phase mini-channel heat exchanger, it is necessary to know the dryout limit for a secure and efficient operation of system.

The main objective of this study is to investigate the influence of different parameters on dryout of propane in minichannels and also to assess the applicability of CHF correlations from the literature for the tested conditions.

Wojtan et al. [4] presented critical heat flux data for 0.5 and $0.8 \mathrm{~mm}$ internal diameter minichannels using R134a and R245fa as working fluids. The results showed increase in CHF with mass flux and no effect of subcooling was observed on CHF. The 


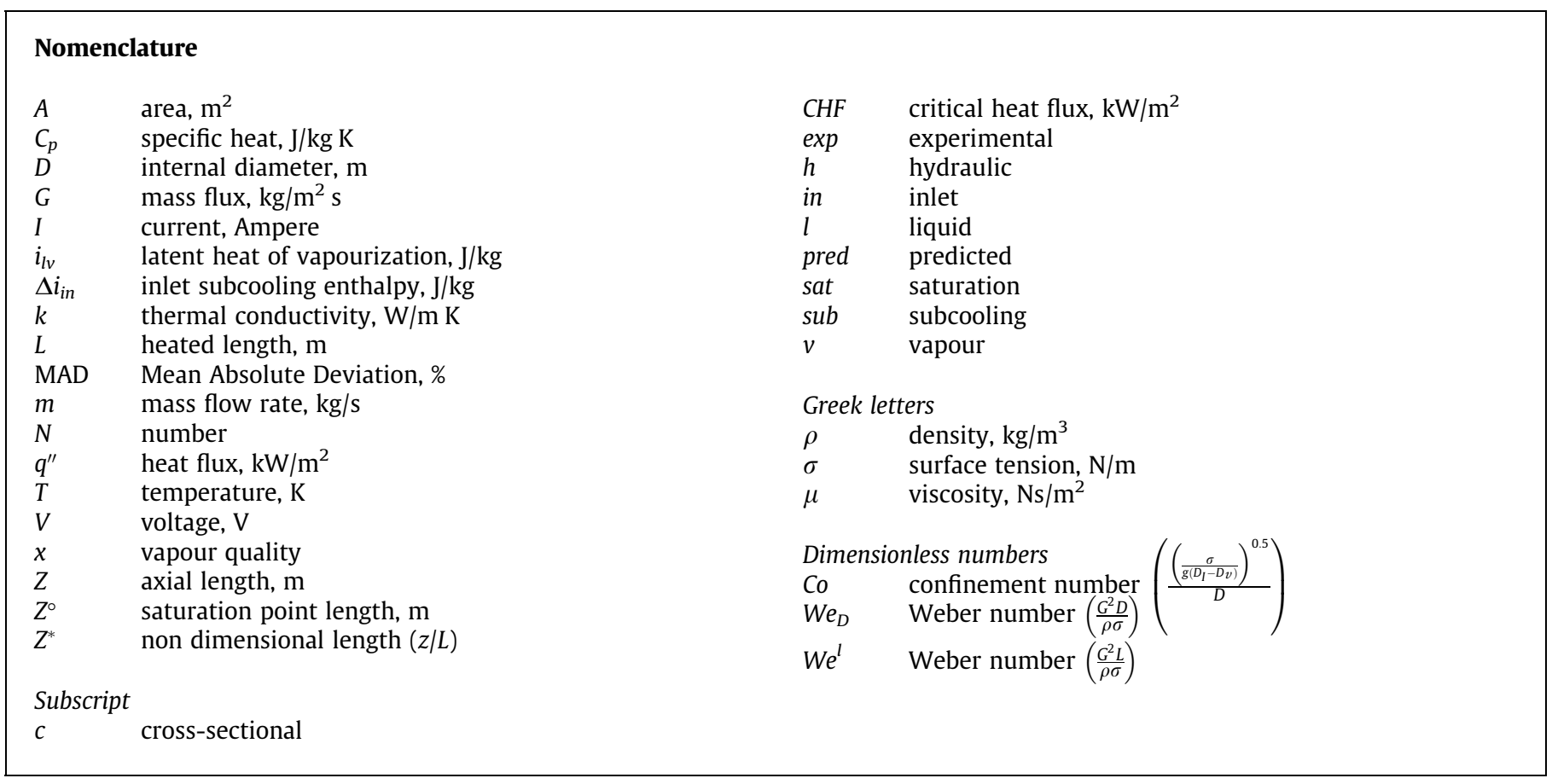

comparison of experimental data with well known correlations showed that Katto and Ohno [5] correlation predicted the data with MAD (Mean Absolute Deviation) of 32.8\%. Based on this correlation, a new correlation was suggested which predicted their experimental data with a MAD of 7.6\%. Ali [6] performed experiments to determine dryout heat flux in vertical circular minichannels with internal diameters of $1.22 \mathrm{~mm}$ and $1.70 \mathrm{~mm}$ with uniformly heated length of $220 \mathrm{~mm}$ using R134a as a working fluid. The dryout heat flux was observed to increase with mass flux and decrease with decrease in tube diameter. The saturation temperature had small influence on the dryout heat flux. The experimental results were compared with some CHF correlations where the Bowring correlation [7] gave the best prediction with a MAD of $13 \%$.

Lazarek and Black [8] presented CHF results using R113 as a working fluid in a vertical circular minichannel of $3.15 \mathrm{~mm}$ internal diameter and heated lengths of 123 and $246 \mathrm{~mm}$. They observed that $\mathrm{CHF}$ occurred due to dryout of liquid film at the exit of the test section. A new CHF correlation was presented which predicted their experimental results with 5\% deviation.

Bowers and Mudawar [9] presented CHF of R113 in an array of circular tubes. No effect of inlet subcooling on CHF was found which was contrary to previous studies found in the literature. Callizo et al. [10] performed experiments to study dryout behaviour, using R134a, R245fa and R22 in a vertical circular micro channel of $0.64 \mathrm{~mm}$ internal diameter. It was found that the saturation temperature has small effect on the dryout heat flux for all working fluids while dryout heat flux was observed to increase with increase in mass flux. Among tested CHF correlations, the Katto and Ohno [5] correlation predicted their experimental results well, with a MAD of $6.7 \%$.

Qi et al. [11] performed flow boiling experiments using liquid nitrogen as working fluid in four mini and micro channels of $0.531,0.834,1.042$ and $1.931 \mathrm{~mm}$ internal diameters. They observed a gradual decrease in CHF with decrease in internal diameter and decrease of mass flux.

Kosar and Peles [12] investigated CHF in a silicon based microchannel heat sink at saturated flow boiling and they observed an increase of CHF with increase in mass flux and decrease in exit quality. CHF was reported to increase with an increase in reduced pressure up to 0.086 , then to decrease. A new correlation was developed which captured the CHF trends in this experimental study with a MAD of $3.8 \%$.

\section{CHF correlations}

Bowring [7] developed a correlation on the basis of about 4000 data points for water. The mathematical form of the correlation is;

$q_{C H F}^{\prime \prime}=\frac{A^{\prime}+0.25 D G \Delta i_{i n}}{C^{\prime}+L}$

$A^{\prime}$ and $C^{\prime}$ are functions of properties and geometrical details which can be seen in detail in [7]. The mathematical form of the CHF correlation proposed by Katto and Ohno [5] is;

$\frac{q_{C H F}^{\prime \prime}}{G i_{l v}}=f\left\{\frac{\rho_{l}}{\rho_{v}}, \frac{\sigma \rho_{l}}{G^{2} l}, \frac{L}{D_{h}}\right\}$

The density ratio in this correlation represents the effects of pressure and $L / D$ ratio shows the geometrical effects. In case of subcooling, they modified the above correlation as;

$\left(q_{C H F}^{\prime \prime}\right)_{s u b}=q_{C H F}^{\prime \prime}\left\{1+\frac{K \Delta l_{i n}}{i_{l v}}\right\}$

$K$ is the empirical inlet subcooling parameter. Different forms of the correlation according to experimental conditions and geometry can be seen in [5].

Shah [13] developed a correlation on the basis of 23 fluids in vertical uniformly heated conventional tubes. This correlation differs from other correlations by the inclusion of viscosity ratio instead of density ratio. According to this correlation, the inlet vapour fraction, $L / D$ ratio, mass flux and viscosity ratio are the major parameters which influence the CHF. Mathematically this correlation can be written as;

$$
\begin{aligned}
& \frac{q_{C H F}^{\prime \prime}}{G i_{l v}}=0.124\left(\frac{L}{D}\right)^{0.89}\left(\frac{10^{4^{n}}}{Y}\right)\left(1-x_{i n}\right) \\
& Y=G^{1.8} D^{0.6}\left(\frac{C_{p}}{k_{l} \rho_{l}^{0.8} g^{0.4}}\right)\left(\frac{\mu_{l}}{\mu_{v}}\right)^{0.6}
\end{aligned}
$$


If $Y \leqslant 10^{4}$ then $n=0$ otherwise for $Y>10^{4}, n$ can be calculated as; For $Y \leqslant 10^{6}, n=\left(\frac{D}{L}\right)^{0.54}$

For $Y>10^{6}, n=\frac{0.12}{\left(1-x_{i n}\right)^{0.5}}$

Callizo et al. [10] presented a correlation for micro channels by adjusting the coefficients in the Katto and Ohno [5] correlation using least square regression analysis. The functional form of this correlation is;

$\frac{q_{C H F}^{\prime \prime}}{G i_{l v}}=0.3216\left(\frac{\rho_{v}}{\rho_{l}}\right)^{0.084} W e_{l}^{-0.034}\left(\frac{L}{D}\right)^{-0.942}$

Wojtan et al. [4] presented another modified version of the Katto and Ohno [5] correlation:

$\frac{q_{C H F}^{\prime \prime}}{G i_{l v}}=0.437\left(\frac{\rho_{v}}{\rho_{l}}\right)^{0.073} W e_{l}^{-0.24}\left(\frac{L}{D}\right)^{-0.72}$

Zhang et al. [14] developed a CHF correlation on the basis of saturated flow boiling data of water at various operating conditions.

$$
\begin{gathered}
\frac{q_{C H F}^{\prime \prime}}{G i_{l v}}=0.0352\left[W e_{D}+0.0119\left(\frac{\rho_{v}}{\rho_{l}}\right)^{0.361}\left(\frac{L}{D}\right)^{2.31}\right]^{-0.295} \\
\left(\frac{L}{D}\right)^{-0.311}\left[2.05\left(\frac{\rho_{v}}{\rho_{l}}\right)^{0.170}-x_{i n}\right]
\end{gathered}
$$

Bowers and Mudawar [9] developed the following CHF correlation for mini and micro channels on the basis of experimental data using R113 as working fluid.

$\frac{q_{C H F}^{\prime \prime}}{G i_{l v}}=0.16 W e_{i}^{-0.19}\left(\frac{L}{D}\right)^{-0.54}$

Qi et al. [11] presented a CHF correlation on the basis of flow boiling of liquid nitrogen data in four mini and micro channels and observed that CHF occurred due to the tear of the liquid film at the inner wall.

$\frac{q_{\mathrm{CHF}}^{\prime \prime}}{G i_{l v}}=(0.214+0.140 \mathrm{Co})\left(\frac{\rho_{v}}{\rho_{l}}\right)^{0.133} W e_{l}^{-0.133} \frac{1}{1+0.03 L / D}$

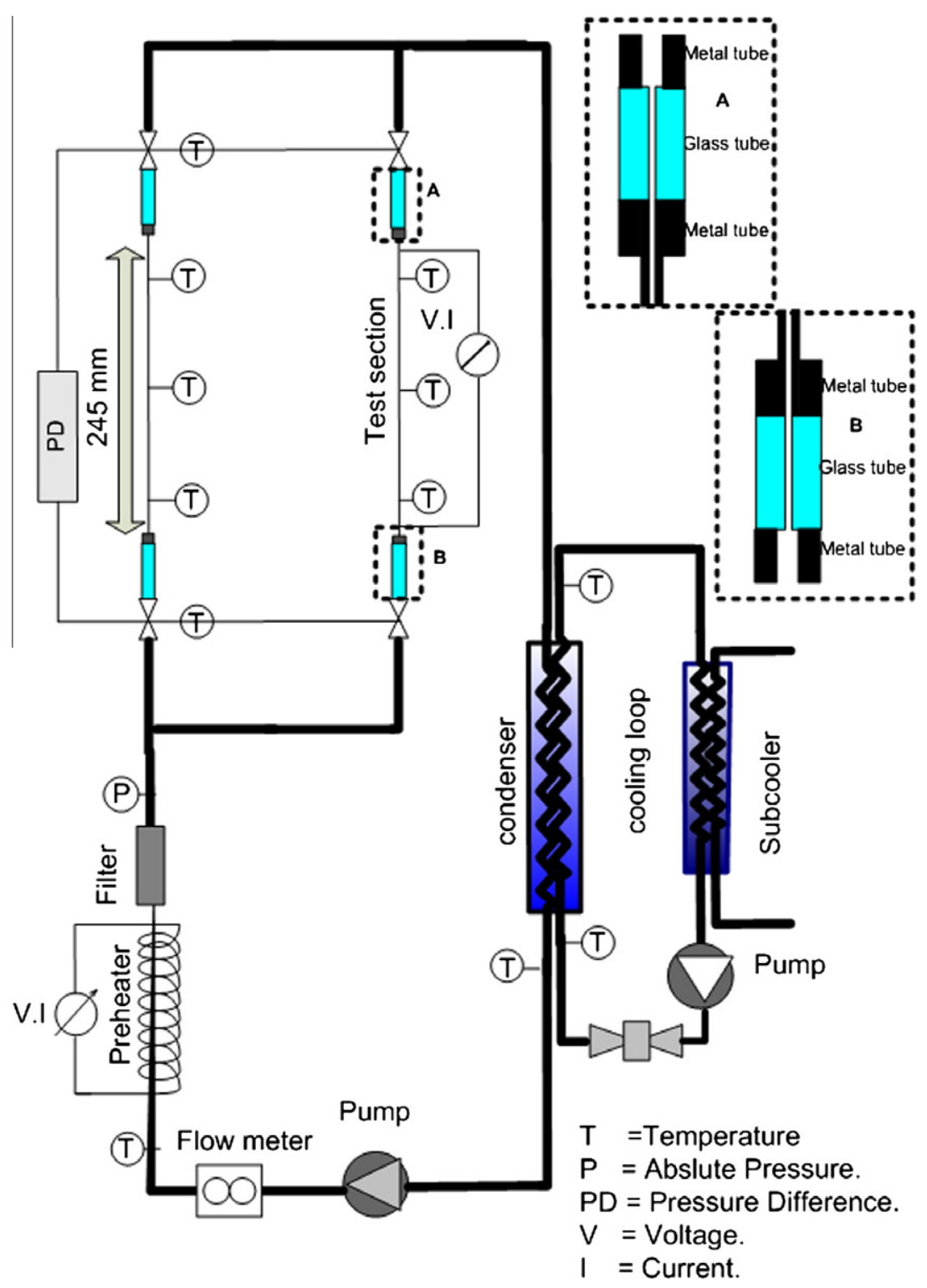

Fig. 1. Schematic diagram of experimental set-up. 


\section{Test rig and experimental procedure}

The layout of the test rig is shown in Fig. 1 and the experimental conditions are tabulated in Table 1 . The experimental set-up consists of a close loop: the subcooler, the magnetic gear pump, the Coriolis mass flow meter, the pre-heater, the test section and the condenser. The subcooler is used to reduce the risk of cavitation at the suction side of the magnetic gear pump. The subcooled refrigerant flows to the inlet of the magnetic gear pump (ISMATEC, type MCP-Z standard). The mass flow rate is controlled by adjusting the speed of the pump and is measured by a Coriolis mass flow meter (MicroMotion, DS006). The refrigerant coming from the mass flow meter enters the pre-heater where it is heated up to the desired inlet temperature. The pre-heater consists of an electric heating coil which is wound around the stainless steel tube in which the refrigerant flows. Before the entry to the test section, a filter of $7 \mu \mathrm{m}$ is installed to restrict any particles from entering the test section. After passing through the test section, the refrigerant enters the condenser for condensation of the vapour back to liquid. After the condenser, the condensate liquid enters the subcooler to complete the loop. The system pressure is maintained constant by regulating the level in the condenser with the use of a heated tank connected to the main loop.

The system pressure is measured by an absolute pressure transducer (Druck PDCR 4060, 20 bar). Two differential pressure transducers (Druck PDCR 2160, 350 and $700 \mathrm{mbar}$ ) are used to measure pressure drop across the two test sections. The refrigerant temperature at the inlet and the outlet of the test section is measured by T-type thermocouples. The test rig is insulated carefully to prevent heat loss to the surrounding. The outer wall temperatures of the test sections are measured by T-type thermocouples. The thermocouples are attached with a special epoxy which is thermally conductive and electrically insulating. The inner wall temperatures are calculated from the measured outer wall temperatures by the one dimensional heat conduction equation for a cylindrical wall, assuming steady state condition, uniform heat generation (Joule Effect) in the tube wall and no heat loss to the surroundings.

The test sections consist of stainless steel (AISI 316) tubes with inner diameters of $1.70 \mathrm{~mm}$ and $1.224 \mathrm{~mm}$ and $245 \mathrm{~mm}$ in length. A glass tube of the same inner diameter as the test section is inserted before and after the test section to visualize the flow regime and to insulate the test section electrically from the test rig. The surface roughness of the test sections were determined by scanning the inner surface using a method called conical stylus profilometry. Five profiles of the inner surface of each test section were obtained and used for the determination of the roughness. The scanned structures of the inner surface of each of the test sections are shown in Fig. 2 and 3. It is observed that the inner surface of the $1.70 \mathrm{~mm}$ tube is smoother than that of the $1.224 \mathrm{~mm}$ diameter tube. The details of the roughness test results are shown in Table 2 , where $R_{a}$ represents the arithmetic mean roughness, $R_{v}$ the maximum valley depth and $R_{p}$ is the maximum peak height.

Table 1

Experimental conditions.

\begin{tabular}{lll}
\hline Test section & Vertical circular minichannels \\
\hline Working fluid & Propane & \\
Inner diameter $(\mathrm{mm})$ & 1.70 & 1.224 \\
Heated length $(\mathrm{mm})$ & 245 & 245 \\
Mass flux $\left(\mathrm{kg} / \mathrm{m}^{2} \mathrm{~s}\right)$ & $100-500$ & $100-400$ \\
Heat flux $\left(\mathrm{kW} / \mathrm{m}^{2}\right)$ & $5-276$ & $5-183$ \\
Saturation temperature $\left({ }^{\circ} \mathrm{C}\right)$ & $23,33,43$ & 33,43 \\
Subcooling $\left({ }^{\circ} \mathrm{C}\right)$ & 1 & 1 \\
\hline
\end{tabular}

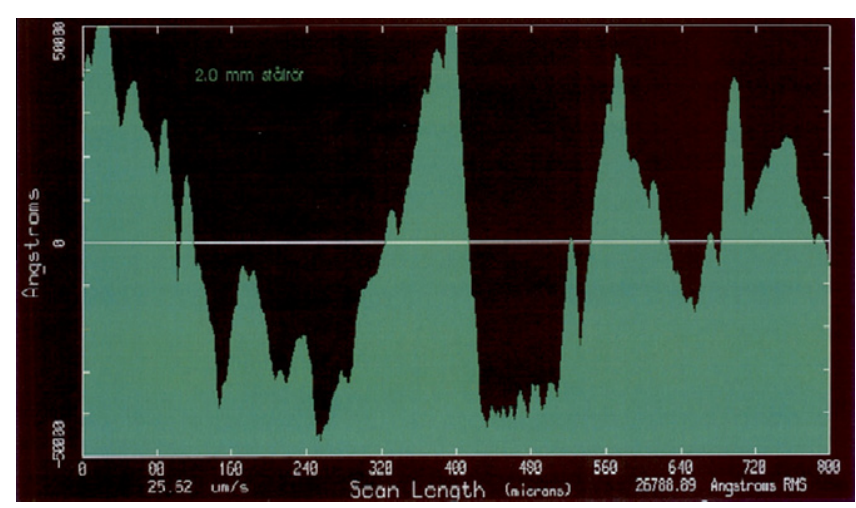

Fig. 2. Characterisation of inner surface roughness of $1.224 \mathrm{~mm}$ test section.

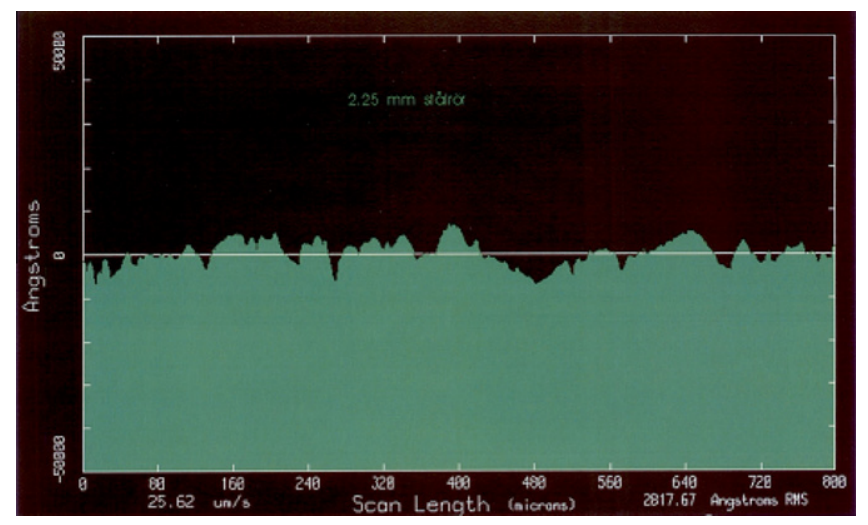

Fig. 3. Characterisation of inner surface roughness of $1.70 \mathrm{~mm}$ test section.

Table 2

Roughness details of test sections.

\begin{tabular}{llll}
\hline Tube inner dimension $(\mathrm{mm})$ & $R_{a}(\mu \mathrm{m})$ & $R_{v}(\mu \mathrm{m})$ & $R_{p}(\mu \mathrm{m})$ \\
\hline 1.70 & 0.21 & -0.73 & 0.80 \\
1.224 & 2.55 & -5.08 & 9.58 \\
\hline
\end{tabular}

All tests are performed at steady state conditions. At the beginning of each test, the system pressure, the mass flow rate and the inlet temperature are set at desired level. Once the parameters are established, the power is applied to the test section. The power is increased gradually in small steps to achieve the desired heat flux. Nearly 100 data points are recorded for $5 \mathrm{~min}$ after steady state conditions are reached. The average values of these data points are used in the calculations. From the recorded parameters, system pressure is used to calculate local saturation pressure and the outer wall temperatures are used to calculate the inner wall temperatures.

\section{Data reduction and uncertainty analysis}

The heat flux is calculated for a given test point as;

$q^{\prime \prime}=\frac{Q-Q_{\text {loss }}}{\pi D L}$

where $Q=l \cdot V$.

$Q$ is the power and $Q_{\text {loss }}$ is the power lost to ambient and were experimentally estimated by the following method: Without any fluid flow, the wall temperatures were set at the desired level by adjusting the electric heating. The data was recorded at different heat fluxes and the temperature difference between wall and 
Table 3

Uncertainty of operating parameters.

\begin{tabular}{lll}
\hline Parameter & Operating range & Uncertainty \\
\hline$D(\mathrm{~mm})$ & $1.70,1.224$ & $\pm 0.007, \pm 0.009$ \\
$G\left(\mathrm{~kg} / \mathrm{m}^{2} \mathrm{~s}\right)$ & $100-500$ & $\pm 3.5 \%$ \\
$q^{\prime \prime}\left(\mathrm{kW} / \mathrm{m}^{2}\right)$ & $5-276$ & $\pm 2 \%$ \\
$T_{\text {sat }}\left({ }^{\circ} \mathrm{C}\right)$ & $23,33,43$ & \pm 0.2 \\
$x$ & $0-1.15$ & $\pm 5 \%$ \\
$C H F\left(\mathrm{~kW} / \mathrm{m}^{2}\right)$ & $55-276$ & $\pm 7 \%$ \\
\hline
\end{tabular}

ambient was plotted versus the applied heat flux. On the basis of the equation of the plot, power loss calculations were done. For low heat fluxes, the power loss was $1-2 \%$ of the applied power and for high heat fluxes it was less than $1 \%$. However, the power loss is subtracted from the imposed power to the test section as shown in Eq. (11).

The vapour quality at any vertical location $(z)$ is determined from the heat transferred to the fluid as;

$x_{z}=\frac{q^{\prime \prime} \cdot \pi D \cdot\left(Z-Z^{\circ}\right)}{A_{C} \cdot G \cdot i_{l v}}$

$Z$ is the desired location where the vapour quality is estimated, $Z^{\circ}$ is the location along the test section where saturated conditions are reached. This point can be determined as;

$Z^{\circ}=\frac{\dot{m} \cdot C_{p} \cdot\left(T_{\text {sat }}-T_{\text {in }}\right)}{q^{\prime \prime} \cdot \pi D}$

The Mean Absolute Deviation (MAD) is used to compare the experimental data with correlations from the literature. These values are calculated as:

$M A D=\frac{1}{N} \sum_{1}^{N} \frac{\left|U_{\text {exp }}-U_{\text {pred }}\right|}{U_{\text {exp }}} \times 100$

$U$ represents the value of experimental or predicted data point. All thermal and transport properties of Propane, including enthalpy, density, viscosity and thermal conductivity, are calculated using REFPROP 7 developed by NIST (National Institute of Standards and Technology).

The uncertainty propagation in the measurement of diameter, tube length, power input, temperature, pressure and mass flow rate is calculated by Engineering Equation Solver (EES). It uses the method suggested in [15]. The propagation uncertainties in the experimental results are tabulated in Table 3.

\section{Results and discussion}

\subsection{Dryout heat flux detection}

The first change of slope in the boiling curve, Fig. 4, indicates departure from nucleate boiling and incipience of dryout. The corresponding heat flux is considered as incipient dryout heat flux. The increase in the wall superheat is a clear indication that dry patches are temporarily formed on the boiling surface. These dryout patches are rewetted by the coming disturbance waves of liquid and this wetting and rewetting continues until complete dryout occurs, if the heat flux is gradually increased. Above the dryout incipience heat flux, heat flux is increased in small steps, ranging from $4 \mathrm{~kW} / \mathrm{m}^{2}$ at the lowest mass fluxes to $10 \mathrm{~kW} / \mathrm{m}^{2}$ at higher mass fluxes, and long enough time is allowed before recording data. These steps are repeated until the wall temperature at the last thermocouple position overshoots more than $25 \mathrm{~K}$ above the saturation temperature. The power applied to the test section is cut off at this point to save the test section from burnout. The measured dryout completion heat flux is not expected to be affected by

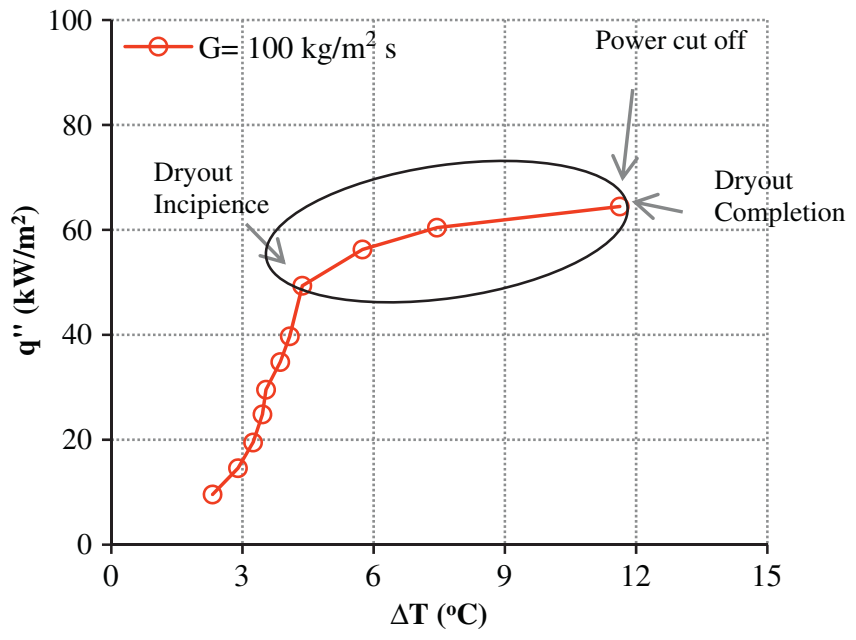

Fig. 4. Boiling curve and identification of dryout incipience and dryout completion of $1.70 \mathrm{~mm}$ diameter tube at $23^{\circ} \mathrm{C}$.

increasing the heat flux to higher wall superheats. Fig. 4 shows the typical boiling curve of the $1.70 \mathrm{~mm}$ tube for $100 \mathrm{~kg} / \mathrm{m}^{2} \mathrm{~s}$ at saturation temperature of $23^{\circ} \mathrm{C}$. The incipience of dryout is clearly visible at a heat flux around $50 \mathrm{~kW} / \mathrm{m}^{2}$. The wall superheat presented in Fig. 4 is the difference between wall and saturation temperature where wall temperature is the average of the recorded temperatures for a particular heat flux at the last thermocouple position, during a short unstable interval, before a sudden sharp increase in temperature recognized as dryout completion.

The occurrence of dryout can also be shown by the temperature profiles of the thermocouples. Fig. 5 shows the temperature profiles of the last six thermocouples of the $1.70 \mathrm{~mm}$ tube for a mass flux of $100 \mathrm{~kg} / \mathrm{m}^{2} \mathrm{~s}$ at a saturation temperature of $23^{\circ} \mathrm{C}$ as a function of recording time. As can be seen large fluctuations in the last two thermocouples indicate dryout and rewetting of the surfaces. The fluctuations start at the downstream end of the test section, then gradually moves upstream with the increase of heat flux. These large fluctuations increase the standard deviation in the temperature readings of the thermocouples. The steady state standard deviation closer to the inlet normally varies from 0.01 to $0.03^{\circ} \mathrm{C}$. Larger and quicker fluctuations are observed in the minichannels in this study than would be expected in macrochannels. The wall temperatures at the last two thermocouples and the corresponding standard deviations as a function of non-dimensional

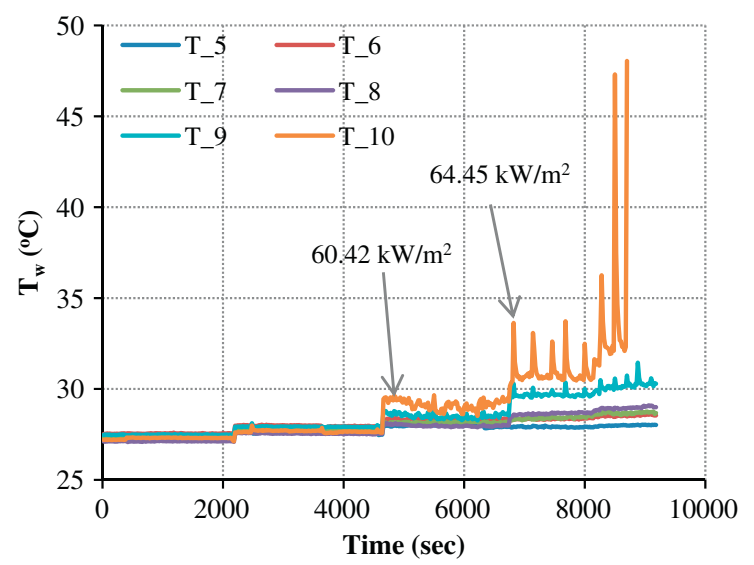

Fig. 5. Temperature profiles near dryout for the last six thermocouples versus time for the $1.70 \mathrm{~mm}$ diameter tube at $23^{\circ} \mathrm{C}$. 
length are plotted in Fig. 6. Teyssedeu et al. [16], Ali [6] and Callizo et al. [10] also reported similar behaviour at the occurrence of dryout in their studies.

\subsection{Effect of mass flux}

Dryout heat flux as a function of mass flux for both tested tubes, at a saturation temperature of $33^{\circ} \mathrm{C}$, is presented in Fig. 7. It can be seen that for both tested tubes, the dryout heat flux increases almost linearly with increase in mass flux. The reason for this is simple; To reach a vapour quality where dryout appears, higher heat flux is needed for higher mass flux. Different authors in previous studies of CHF in the literature such as Wojtan et al. [4], Kosar and Peles [12], Calizzio et al. [10] and Ali [6] have also reported the similar trends.

\subsection{Effect of vapour quality and saturation temperature}

Dryout heat flux as a function of vapour quality at the last thermocouple location for the $1.70 \mathrm{~mm}$ internal diameter tube is plotted in Fig. 8 for a mass flux range of $200-400 \mathrm{~kg} / \mathrm{m}^{2} \mathrm{~s}$ and the saturation temperatures of 23,33 and $43{ }^{\circ} \mathrm{C}$. It can be seen that there are two vapour qualities joined by a line for each case. The lower vapour quality represents the dryout incipience and the higher vapour quality represents the dryout completion. Dryout

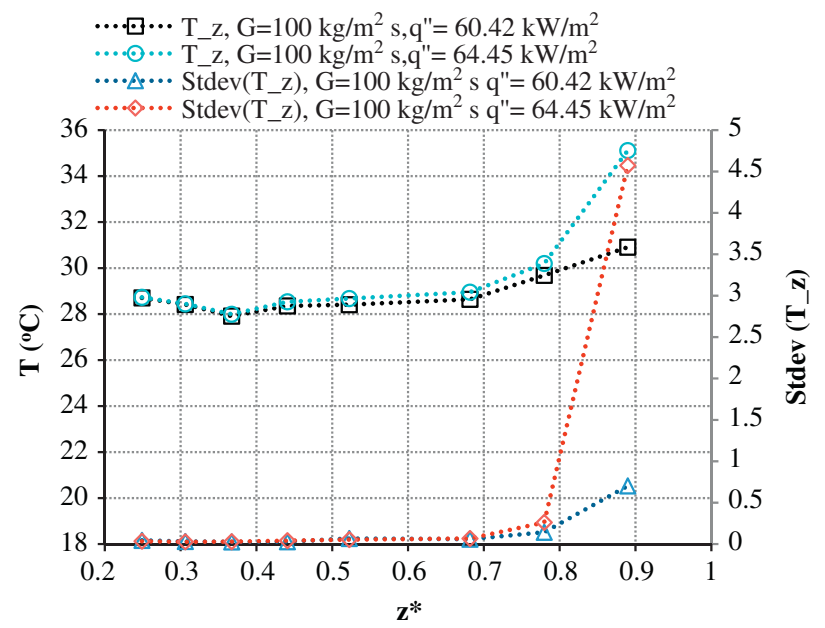

Fig. 6. Temperature readings and corresponding standard deviations of the $1.70 \mathrm{~mm}$ diameter tube at $23^{\circ} \mathrm{C}$ near dryout completion.

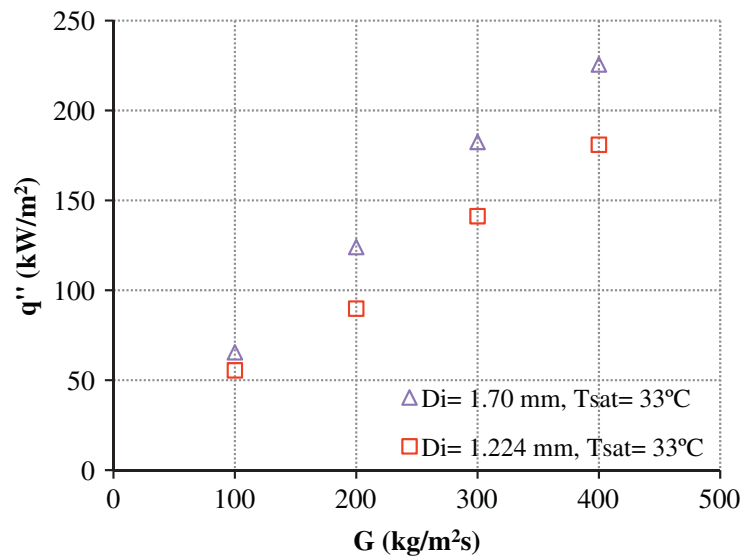

Fig. 7. Effect of mass flux on dryout heat flux for both test sections. incipience vapour quality represents the heat flux where the fluctuations in the readings of the last thermocouple on the downstream side of the test section started. At this point the standard deviation of the last thermocouple data increased above the steady state standard deviation; dryout completion vapour quality represents the heat flux where the temperature reading of the last thermocouple increased sharply after a short instable time period more than $25 \mathrm{~K}$ above the saturation temperature and the power to the test section was cut off to save the test section. It is also observed that for a given saturation temperature, the dryout incipience occurs at lower vapour quality for higher mass flux except for $400 \mathrm{~kg} / \mathrm{m}^{2} \mathrm{~s}$ at $43^{\circ} \mathrm{C}$ saturation temperature where the incipience of dryout is delayed to higher vapour quality. A decrease in dryout completion vapour quality at higher mass flux is also observed for a given saturation temperature. According to our previous studies $[6,18]$ in which the flow regimes along a minichannel were studied, initiation of annular flow was found to start at much lower qualities than those at dryout. It has been suggested that, in annular flow, an increase in mass flow increases the droplet entrainment in the vapour core [17], thereby reducing the amount of liquid in the film, and thus also the film thickness. The liquid film may then break due to this droplet entrainment and the channel wall can be exposed to the vapour. This can be a reason for the decrease in dryout completion vapour quality at higher mass fluxes. From Fig. 8, it can also be seen that for a given mass flux, the vapour quality at dryout incipience and dryout completion increases with increase in saturation temperature except for $200 \mathrm{~kg} / \mathrm{m}^{2} \mathrm{~s}$, where the vapour quality at dryout completion at $23{ }^{\circ} \mathrm{C}$ is marginally higher than at $33^{\circ} \mathrm{C}$. The occurrence of dryout incipience and dryout completion at higher vapour qualities for higher saturation temperature at a given mass flux can be explained by the increase of vapour to liquid density ratio with saturation temperature which can reduce the droplet entrainment rate in the vapour core resulting in a delay of dryout occurrence [6].

Fig. 9 presents heat flux versus vapour quality at the last thermocouple, for the mass flux range $200-400 \mathrm{~kg} / \mathrm{m}^{2} \mathrm{~s}$ and the saturation temperatures $33^{\circ} \mathrm{C}$ and $43{ }^{\circ} \mathrm{C}$ in the $1.224 \mathrm{~mm}$ internal diameter tube. It can be seen that for a given mass flux, the vapour quality at dryout incipience increases with increase in saturation temperature. As in the $1.70 \mathrm{~mm}$ tube, it is also observed here that, generally dryout vapour quality is lower for higher mass flux which has been explained in previous paragraph. Wojtan et al. [4] and Kosar and Peles [12] have also observed general trends as in this study.

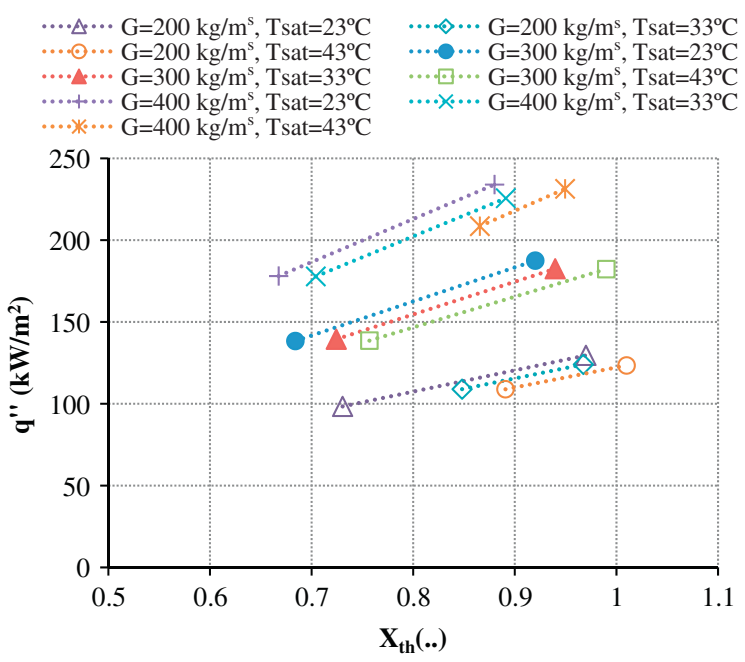

Fig. 8. Effect of vapour quality on heat flux at dryout incipience and dryout completion for the $1.70 \mathrm{~mm}$ diameter tube. 


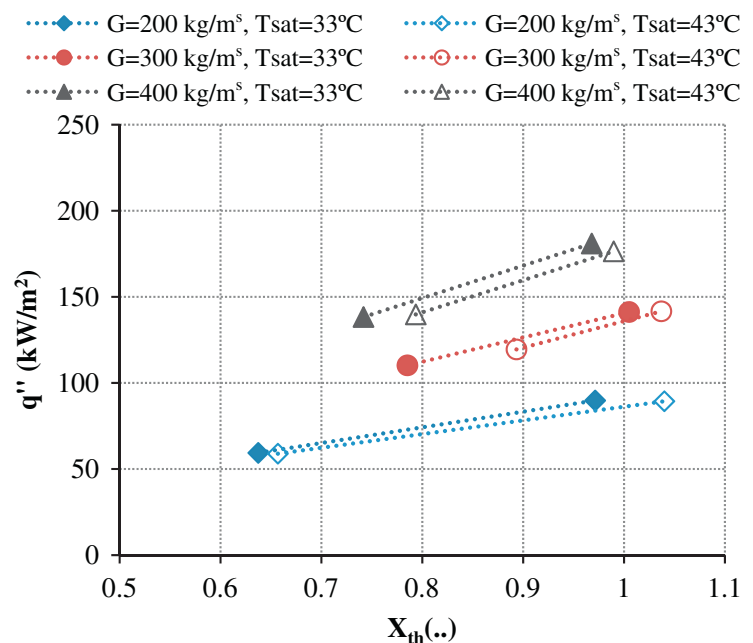

Fig. 9. Effect of vapour quality on heat flux at dryout incipience and dryout completion for the $1.224 \mathrm{~mm}$ diameter tube.

The effect of saturation temperature on the dryout heat flux can also be discussed from Fig. 8 and 9. It can be seen from Fig. 8 for the $1.70 \mathrm{~mm}$ tube that the effect of saturation temperature on dry out incipience is not clear. Incipience of dryout occurs at different heat fluxes at different saturation temperatures with no clear trend. However, the differences in heat flux are small. It can also be seen that complete dryout occurs almost at the same heat flux for all saturation temperatures. Fig. 9 for the $1.224 \mathrm{~mm}$ tube shows also small differences for heat flux at both incipience and completion of dryout. It can be concluded from Figs. 8 and 9 that there is insignificant effect of saturation temperatures on dryout heat flux. The vapour to liquid density ratio is directly proportional to saturation temperature and the latent heat of vapourization is inversly proportional to saturation temperature. In famous Katto and Ohno [5] correlation, vapour to liquid density ratio and latent heat of vapourization are also in linear relationship with critical heat flux. The increase in vapour to liquid density with saturation temperature tends to reduce the droplet entrainment rate in the vapour core which may increase the dryout heat flux [6]. The decrease in latent heat of vapourization with saturation temperature tends to reduce dryout heat flux [12]. The mentioned effects may be two opposite contributors cancelled to diminish the effect of saturation temperature on dryout heat flux.

\subsection{Effect of tube diameter}

The effect of tube diameter on the dry out heat flux is depicted in Fig. 10 where heat flux is plotted versus vapour quality for a range of different mass fluxes for the $1.70 \mathrm{~mm}$ and $1.224 \mathrm{~mm}$ internal diameter tubes. It can be seen that for a given mass flux, complete dryout heat flux is considerably higher for the larger diameter channel. For given experimental conditions, the liquid film may break faster in the lower diameter tube due to higher shear force than in the higher diameter tube. This can be a reason for the increase in complete dryout heat flux with the increase of internal diameter. The effect of diameter can also be seen in Fig. 7 where heat flux is plotted versus mass flux for both test sections at $33^{\circ} \mathrm{C}$ saturation temperature.

Another point worth noting in Figs. 8-10 is that the dryout completion vapour qualities in some cases are above 1 . This can be explained by fluctuations in mass flux on the downstream side of the test section as a result of waves of liquid from upstream periodically wetting the test section up to a point where, on the average, the vapour quality is higher than 1 (cf Fig. 5).

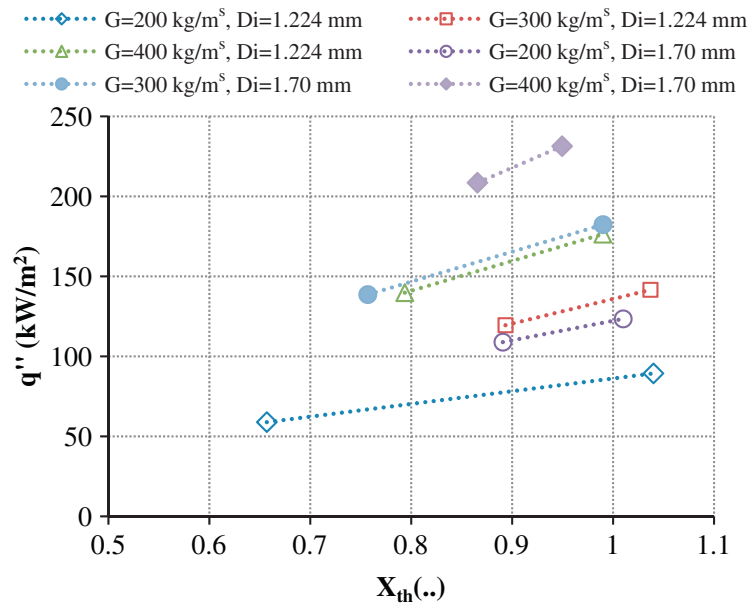

Fig. 10. Effect of channel diameter on heat flux for dryout incipience and dryout completion at $43^{\circ} \mathrm{C}$ saturation temperature.

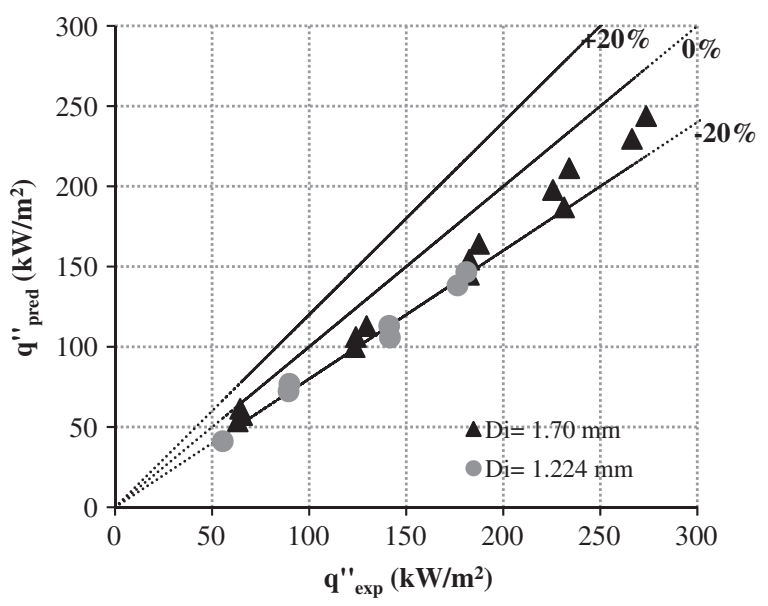

Fig. 11. Comparison of experimental data with Katto and Ohno correlation [5].

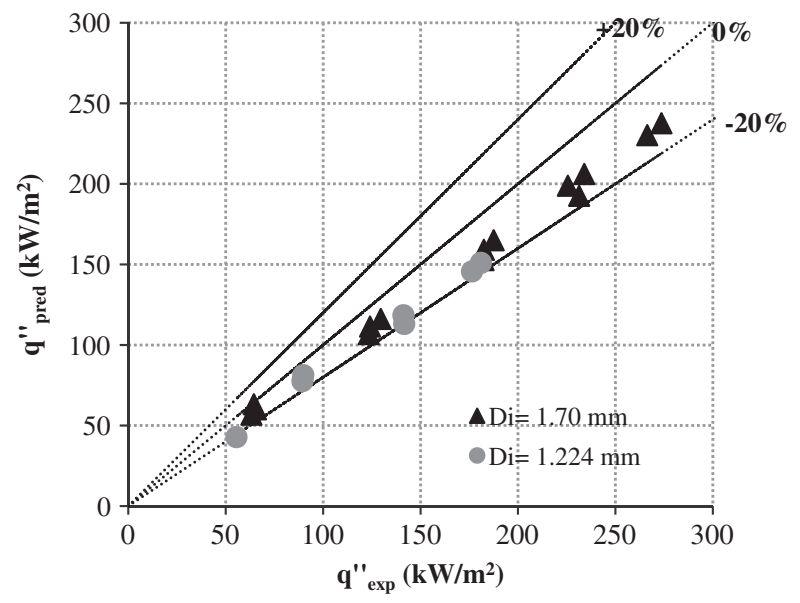

Fig. 12. Comparison of experimental data with Bowring correlation [7].

\section{Comparison with correlations}

To avoid burnout of the installed facility due to dryout, in cases where the heat flux rather than the temperature is given by the application, it is very important to have a good predicting model 


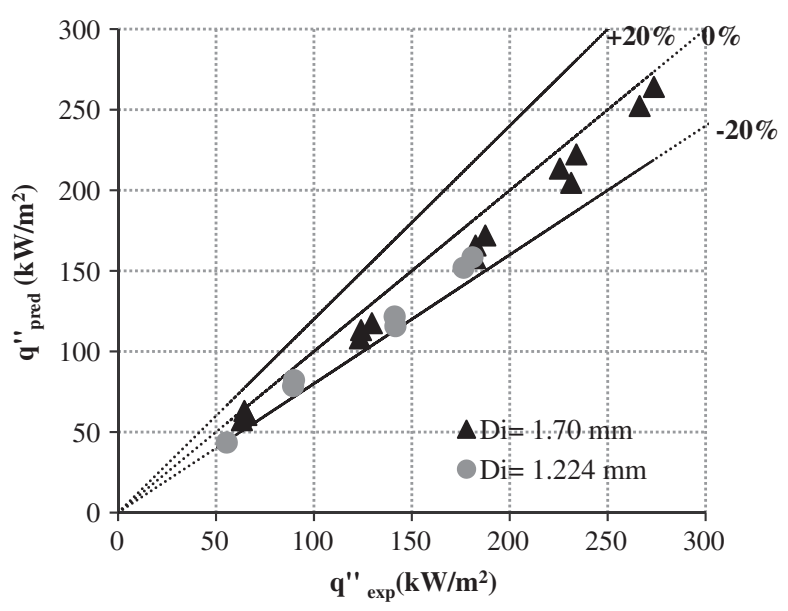

Fig. 13. Comparison of experimental data with Callizo et al. correlation [10].

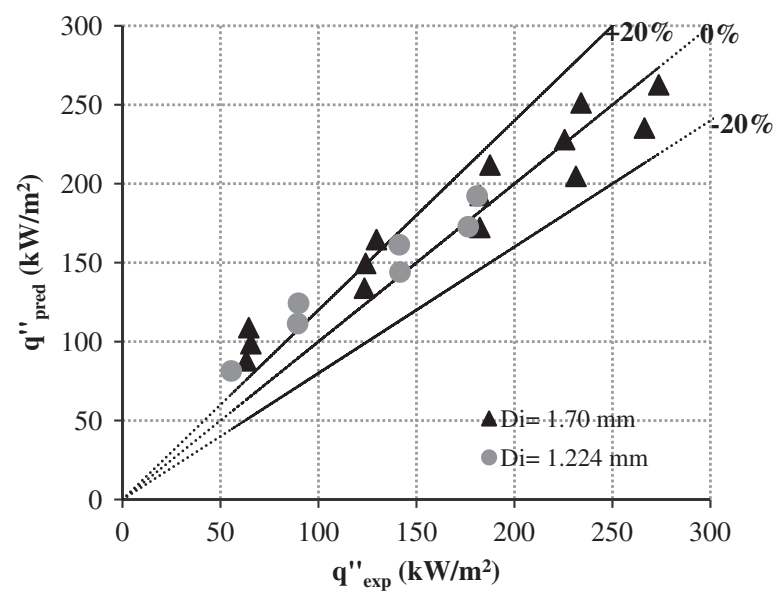

Fig. 14. Comparison of experimental data with Bowers and Mudawar correlation [9].

which can predict the complete dryout heat flux condition to minimize the risk of accidents. In this section, an effort has been made to compare our experimental data of complete dryout with well known verified predicting methods for macro channels which have been used for decades, like the correlations by Katto and Ohno [5], Bowring [7], and Shah [13], to see their applicability in minichannels. The experimental data is also compared with predicting methods which are developed specifically for mini and microchannels like Callizo et al. [10], Bowers and Mudawar [9], Qi et al. [11], Zhang et al. [14] and Wojtan et al. [4].

Fig. 11 shows the comparison of the experimental data with Katto and Ohno correlation [5] at all three saturation temperatures for the $1.70 \mathrm{~mm}$ and the $1.224 \mathrm{~mm}$ internal diameter tubes. This correlation has been developed for macro channels using data of different fluids like water, nitrogen, helium, R22, R113 and R12 and as can be seen, it predicts the data reasonably well with a MAD of $16 \%$ and about $81 \%$ of the data is within $\pm 20 \%$ range.

Bowring [7] developed his CHF correlation from data of water for large diameter tubes. This correlation has been derived from data covering system pressure up to 190 bar and mass velocity up to $186000 \mathrm{~kg} / \mathrm{m}^{2} \mathrm{~s}$. This correlation predicts the experimental data with a MAD of $13 \%$ and $91 \%$ of the experimental data points are in the $\pm 20 \%$ range. The predictions of Bowring correlation [7] are presented in Fig. 12.

Callizo et al. [10] proposed a modified version of Katto and Ohno [5] correlation for micro scale flow. This correlation gives
Table 4

Assessment of correlations.

\begin{tabular}{lll}
\hline Correlation & MAD (\%) & \% of data within $\pm 20 \%$ \\
\hline Katto and Ohno [5] & 16 & 81 \\
Shah [13] & 37 & 0 \\
Bowring [7] & 13 & 91 \\
Callizo et al. [10] & 10 & 95 \\
Wojtan et al. [4] & 34 & 19 \\
Zhang et al. [14] & 22 & 33 \\
Qi et al. [11] & 36 & 57 \\
Bowers and Mudawar [9] & 19 & 62 \\
\hline
\end{tabular}

the best predictions among the correlations investigated in this article with a MAD of $10 \%$ and $95 \%$ of the experimental data is within the $\pm 20 \%$ range as is shown in Fig. 13 . This correlation has been developed on the basis of experimental data of R134a taken on the same test rig as used in this. This can be a reason why this correlation predicts the data well.

The correlation proposed by Bowers and Mudawar [9] predicts all the experimental data with a MAD of $19 \%$ and about $62 \%$ of the experimental data is within $\pm 20 \%$. It should be noted that the length to diameter ratio used for the $1.70 \mathrm{~mm}$ tube in this study is comparable to the length to diameter ratio used by Bowers and Mudawar [9]. The predictions of this correlation are compared to the experimental data in Fig. 14.

A summary of the comparison with all used correlations in this study, including Shah [13], Wojtan et al. [4], Zhang et al. [14], and Qi et al. [11] are tabulated in Table 4.

\section{Conclusions}

Experiments have been performed to determine the dryout characteristics of Propane in single vertical circular minichannels of $1.70 \mathrm{~mm}$ and $1.224 \mathrm{~mm}$ internal diameter and a uniformly heated length of $245 \mathrm{~mm}$.

Generally the experimental results show that the dryout heat flux increases with increase of mass flux and with decrease of vapour quality for both tested tubes. It has also been shown that the dryout heat flux is almost independent of saturation temperature, but that dryout occurs at slightly higher vapour quality for higher saturation temperature at a given mass flux. The dryout heat flux is observed to be higher for the larger internal diameter tube for the same mass flux.

The experimental results are compared with some correlations from the literature. Among those the correlations developed by Callizo et al. [10], Bowring [7], Katto and Ohno [5] and Bowers and Mudawar [9] predicted the experimental results reasonably well.

\section{Acknowledgement}

The authors gratefully acknowledge the scholarship awarded by the Higher Education Commission Pakistan [HEC] to conduct this research as part of PhD studies at the Department of Energy Technology, Royal Institute of Technology, KTH, Sweden.

\section{References}

[1] P. Fernando, B. Palm, T. Ameel, P. Lundqvist, E. Granryd, A mini channe aluminium tube heat exchanger - Part 2: Evaporator performance with propane, Int. J. Refrig. 31 (4) (2007) 681-695.

[2] S.G. Kandlikar, Critical heat flux in subcooled flow boiling-an assessment of current understanding and future directions for research, J. Multiphase Sci. Technol. 13 (3) (2001) 207-232.

[3] J.G. Collier, J.R. Thome, Convective Boiling and Condensation, third ed., Oxford university press, 1994. 
[4] L. Wojtan, R. Revellin, J.R. Thome, Investigation of saturated critical heat flux in a single, uniformly heated microchannel, Exp. Therm. Fluid Sci. 30 (2006) 765-774.

[5] Y. Katto, H. Ohno, An improved version of the generalized correlation of critical heat flux for forced convective boiling in uniformly heated vertical tubes, Int. J. Heat Mass Transfer 27 (1984) 1641-1648.

[6] R. Ali, Phase Change Phenomena during Fluid Flow in Micro Channels, Doctoral Thesis in KTH, ISBN 978-91-7415-829-8, Stockholm, 2010.

[7] R.W. Bowring, A Simple but Accurate Round Tube Uniform Heat Flux Correlation over the Pressure Range $0.7-17 \mathrm{MN} / \mathrm{m}^{2}$, Report AEEW-R789, Winfrith, UK, 1972.

[8] G.M. Lazarek, S.H. Black, Evaporative heat transfer, pressure drop and critical heat flux in a small vertical tube R-113, Int. J. Heat Mass Transfer 25 (1982) 945-960.

[9] M.B. Bowers, I. Mudawar, High flow boiling in low flow rate, low pressure drop mini-channel and micro-channel heat sinks, Int. J. Heat Mass Transfer 37 (1994) 321-332.

[10] C.M. Callizo, R. Ali, B. Palm, Dryout incipience and critical heat flux in saturated flow boiling of refrigerants in a vertical uniformly heated micro channels, in: Proc. of the Sixth Int. ASME Conference on Nano, Micro and Mini channels, ICNMM, Darmstadt, Germany, 2008.
[11] S.L. Qi, P. Zhang, R.Z. Wang, L.X. Xu, Flow boiling of liquid nitrogen in micro tubes: Part II - Heat transfer characteristics and critical heat flux, Int. J. Heat Mass Transfer 50 (2007) 5017-5030.

[12] A. Kosar, Y. Peles, Critical heat flux of R123 in silicon based micro channels, ASME J. Heat Transfer 129 (7) (2007) 844-851.

[13] M.M. Shah, Improved general correlation for critical heat flux during upflow in uniformly heated vertical tubes, Int. J. Heat Fluid Flow 8 (4) (1987) 326-335.

[14] W. Zhang, T. Hibiki, K. Mishima, Y. Mi, Correlation of critical heat flux for flow boiling of water in mini-channels, Int. J. Heat Mass Transfer 49 (2006) 10581072 .

[15] B.N. Taylor, C.E. Kuyatt, Guidelines for Evaluating and Expressing the Uncertainty of NIST Measurement Results, NIST Tech. Note 1297, 1994.

[16] A. Teyssedeu, A. Olekhnowitch, A. Tapucu, A. Champagne, D. Groenveld, Critical heat flux data in a vertical tube at low and medium pressures, J. Nucl. Eng. Des. 149 (1994) 185-194.

[17] V.P. Carey, Liquid-Vapor Phase Change Phenomena, Hemisphere, New York, 1992.

[18] W. Owhaib, Experimental Heat Transfer, Pressure Drop and Flow Visualization of R-134a in Vertical Mini/Micro Tubes, Doctoral Thesis in KTH, ISBN 978-917178-594-7, Stockholm, 2007. 